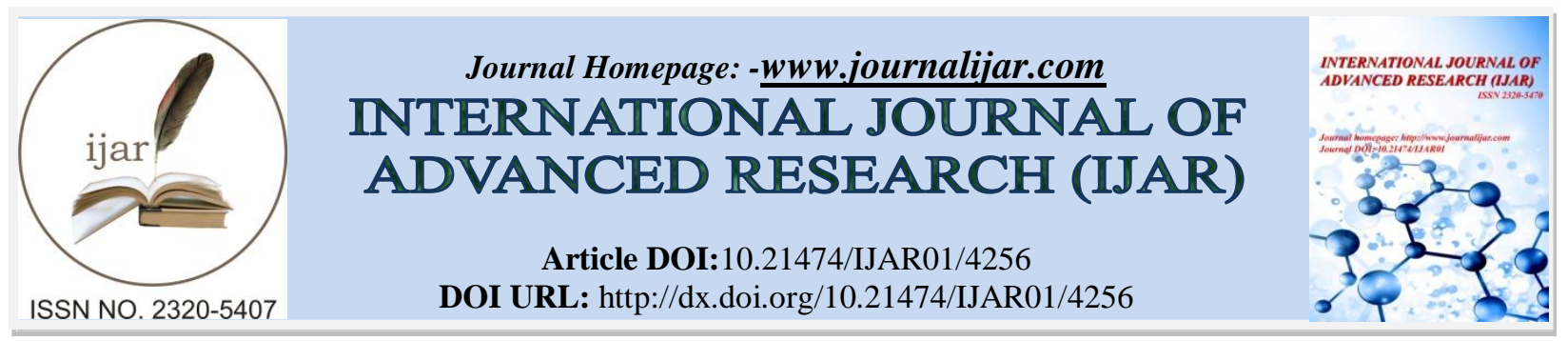

RESEARCH ARTICLE

\title{
REDUCINGSEXUAL MALES DYSFUNCTION USING NATURAL FOODS.
}

Makpoul .K.R.

Food science and technology - Agricultural industrializationunite,Department of Plant Production - Desert Research Center - Cairo -Egypt

\section{Manuscript Info}

Manuscript History

Received: 26 March 2017

Final Accepted: 29 April 2017

Published: May 2017

Key words:-

Angelica sinensis, calycotomevillosa, date paste, dietary supplement, male dysfunction, monoamine oxidase (MAO-

B), Phosphodiesterase (PDE-5),

testosterone

\section{Abstract}

Lack of important vitamins and mineral in unhealthy food lead to a disturbance in testosterone level, also lead to an increase in the activity of each enzyme monoamine oxidase (MAO-B) which responsible for depression, and Phosphodiesterase (PDE-5) which enzyme res2aqponsible for low blood flow to peripheral vascular. Despite the prevalence of drugs to this problem did not reach the level of satisfaction of the efficacy and safety effects.in this study, male sexual dysfunction has required the agent that is effective, cheap and easy. Though natural food is reputed for aphrodisiac activity in traditional folklore, no scientific evidence is available. Therefore, we aimed to determine the effect of date paste with Angelica sinensis and calycotomevillosa as dietary supplement on male dysfunction in animal model.Our data showed a significant increase in serum testosterone level. However, also suppress MAOB and PDE-5 activities. Taken all together, the natural dietary supplement could enhance male sexual desire and performance via the increased of testosterone level suppression of MAOB and PDE-5 activities.

Copy Right, IJAR, 2017,. All rights reserved.

\section{Introduction:-}

Increasing sexual dysfunction in males with age, which is considered as one of the Important in human life and social relationship, It effects of Millions of men all over the world (Moreira et al 2006, Wattanathorn et al 2012). Despite the prevalence of drugs to this problem, but did not reach the level of satisfaction of the efficacy and safety also had many side effects. Therefore, The sexual dysfunction consists of two main problems the first problem is Erectile Dysfunction (ED) is the most commonly found after the age of forty. The second problem, which is a short ejaculation latency: The time interval between the primary intromission and ejaculation, However, it refers to a problem during any phase of the sexual response (Glenville, M., 2008).

Causes of sexual dysfunction to many, but the ones primarily within these categories, Issues blood circulation, Hormone Issues, Side-effects of Certain Medicines, Nerve Issues and Psychological Issues (Anthony 2010). An aphrodisiac is a type of food or drink that makes those who eat or drink mo0re raised in a sexual manner. Aphrodisiacs can be classified according to the mode of action into three groups: Substances that increase sexual desire and arousal, and materials increase the sexual potency of any effectiveness of Erection and materials that increase sexual pleasure.

Corresponding Author:-Makpoul .K .R. 
Dates palm the most important foods that are working on regulating the hormones' activity of into the body as it is rich of important vitamins and minerals, date palm contains estradiol and flavonoid components that have positive effects on the sperm quality, enhance fertility in the male adult rat. Therefore, it may be useful to solve infertility problems (Neelesh et al 2011).

Angelica sinensis (Dong quai) root contains (0.4-0.7) percent volatile oil, the key components of which are nbutylidenephthalide, ligustilide, n-butylphthalide, ferulic acid, nicotinic acid, and succinic acid (Duke 1992, Skidmore 2001, Zhu 1987). Significant amounts of vitamin A and carotenoids (0.675\%), vitamin B12 (0.25-0.40 mcg/100 g), vitamin E, ascorbic acid, folinic acid, biotin, various phytosterols (e.g., beta-sitosterol), calcium, magnesium, and other essential macrominerals are also found in dong quai root (Huang 1999). Other constituents include $\mathrm{n}$ valerophenone-O-carboxylic acid, delta-2,4-dihydrophthalic anhydride, uracil, adenine, carvacrol, safrole, isosafrole, sesquiterpenes, beta-cadinene, n-dodecanol, $\mathrm{n}$ tetradecanol, palmitic acid, angelic acid, myristic acid, sucrose (40\%), and a polysaccharide with a molecular weight of approximately 3,000 (Tyler 1995). Due to its varied constituents, several pharmacological actions may be attributed to dong quai. Such characteristics include anticoagulation and antiplatelet activity, as well as hematopoiesis, immune support, and males dysfunction. (Chang \& But 1987, Der \&Beutler 2004, Wilasrusmee et al 2002a, Wilasrusmee et al 2002b).

Calycotomevillosa (Kandol) a common pioneer Leguminosae, with yellow flowers during the spring season, very familiar in the Mediterranean area, where it grows near the sea (1.2 m altitude). The aerial parts of the plant were collected during the flowering season, which is used as a drink to overcome the low blood pressure and increase the flow to the peripheral parts. Calycotomevillosa a collective pioneer Leguminosae, with yellow flowers during the spring season, very communal in the Mediterranean area, where it grows near the sea (1.2 $\mathrm{m}$ altitude). The aerial parts of the plant were collected during the flowering season, which is used as a drink to overcome the low blood pressure and increase the flow to the peripheral parts.( Juan et al 2008).

\section{Materials and Methods:-}

Plant material preparation:-

> The roots of Angelica sinensis were collected from Elmaghara in Middle Sinai, and stored at $20 \mathrm{C}$.

$>$ The leaves and flowers of calycotomevillosa were collected from Elmaghara in Middle Sinai, and stored at 20 C.

$>$ Angelica sinensis root $(500 \mathrm{~g})$ and calycotomevillosa leaves and flowers $(500 \mathrm{~g})$ were dried and at $60^{\circ} \mathrm{C}$. Dried samples were ground to pass through a 60-mesh sieve using an analytical mill to fine powder.

$>$ Date paste was obtained from El-Nour for food industry in North Sinai.

\section{preparation of dietary supplement:-}

Dietary supplements were prepared as follows:

$>$ Concentration (A) : Addition and thorough mixing of $30 \mathrm{~g}$ of date paste $+0.25 \mathrm{~g}$ of Angelica sinensis root powder $+0.25 \mathrm{~g}$ of calycotomevillosa leaves and flower's powder.

$>$ Concentration (B) : Addition and thorough mixing of $30 \mathrm{~g}$ of date paste $+0.50 \mathrm{~g}$ of Angelica sinensis root powder $+0.50 \mathrm{~g}$ of calycotomevillosa leaves and flower's powder.

$>$ Concentration (C) : Addition and thorough mixing of $30 \mathrm{~g}$ of date paste $+0.75 \mathrm{~g}$ of Angelica sinensis root powder $+0.75 \mathrm{~g}$ of calycotomevillosa leaves and flower's powder.

$>$ Concentration (D) : Addition and thorough mixing of $30 \mathrm{~g}$ of date paste $+1 \mathrm{~g}$ of Angelica sinensis root powder + $1 \mathrm{~g}$ of calycotomevillosa leaves and flower's powder.

\section{Animal and diet protocol:-}

Ninety (90) Healthy male rats (250 to $300 \mathrm{~g}$ ) were selected for the experiment. and were housed in standard metal cages at $22 \pm 2{ }^{\circ} \mathrm{C}$ on $10: 14 \mathrm{~h}$ light-dark cycle. All animals were given access to food and water. The rats were divided into six groups each group consists of fifteen rats.

Date paste (dietary supplement) with different concentrations processing in the water doses formed, Mixing date paste (dietary supplement) with $100 \mathrm{ml}$ water and divided into 3 doses. Each dose $30 \mathrm{ml}$ gives it to the mice at three times per day as a full dose to ensure mice eating a full sample.

Fed mice groups for 30 days explained below:

Group 1: was fed by basic meals only which was used as negative control. 
Group 2: was fed bydietary supplement concentration (A) Group 3: was fed bydietary supplement concentration (B) Group 4: was fed bydietary supplement concentration (C) Group 5: was fed bydietary supplement concentration (D) Group 6: was fed by Sildenafil citrate $50 \mathrm{mg}$ which was used as positive control

\section{Determination of vitamins in plant sample:- Determination of Fat-Soluble Vitamins:-}

In $10 \mathrm{~g}$ plant samples and dietary supplement powder, $1 \mathrm{~g}$ of pyrogallic acid, $70 \mathrm{~mL}$ ethanol, and $30 \mathrm{~mL}(50 \%) \mathrm{KOH}$ were added, stirred, and refluxed for 40min using a water bath at $50 \pm 2 \mathrm{C}$ (Aumaporn, 2009, Jun et al 2007). Extracts were obtained three times using various ether concentrations $(50 \mathrm{~mL}, 30 \mathrm{~mL}$, and $20 \mathrm{~mL})$. Double-distilled water was used to neutralize the extract, which was dehydrated using anhydrous sodium sulfate. Further, the extract was concentrated to approximately $5 \mathrm{~mL}$ by using a water bath $(50 \pm 2 \mathrm{C})$, diluted to $10 \mathrm{~mL}$ by using methanol, filtered using a $0.45 \mu \mathrm{m}$ membrane, and finally subjected to HPLC analysis. RP-HPLC analysis was performed with the Agilent 1100 series HPLC system (Agilent; USA), including a diode array detector. The column was made of stainless steel. For fat-soluble vitamins, the Agilent Eclipse XDB-C18 column was used (5 $\mu \mathrm{m}, 4.6 \times 150 \mathrm{~mm})$, V (B12), the solvent was methanol, and UV detection was recorded at $325 \mathrm{~nm}$ for vitamin A, 265nm for vitamin D3, $290 \mathrm{~nm}$ for vitamin E, and $244 \mathrm{~nm}$ for vitamin K3. Separation of all vitamins was based on isocratic elution and the solvent flow rate was maintained at $1 \mathrm{~mL} / \mathrm{min}$.

Twenty microliters of sample's oil were directly injected into the HPLC column. Fat-soluble vitamins were identified by comparing their retention times with those of authentic standards. All procedures were carried out under subdued light conditions. Standard solutions of vitamins were prepared by serial dilution to concentrations of $0.1,1,2,5$, and 10mg per liter of vitamins D3, E, K3 and A , respectively. Standard solutions were prepared daily from a stock solution, which was stored in the dark at -20C. Twenty microliters of standard solution were injected, and peak areas were determined to generate standard curves.

\section{Determination of Water-Soluble Vitamins: \\ Determination of Vitamin B group:-}

The vitamin B group was extracted according to a previously described method [20]. Plant samples and dietary supplement powder $(2 \mathrm{~g})$ was placed in $25 \mathrm{~mL}$ of $\mathrm{H} 2 \mathrm{SO} 4(0.1 \mathrm{~N})$ solution and incubated for 30min at $121 \mathrm{C}$. Then, the contents were cooled and adjusted to $\mathrm{pH} 4.5$ with $2.5 \mathrm{M}$ sodium acetate, and 50mg enzymatic hydrolysis was added. The preparation was stored at $35 \mathrm{C}$ overnight. The mixture was then filtered through a Whatman No. 4 filter, and the filtrate was diluted with $50 \mathrm{~mL}$ of pure water and filtered again through a micropore filter $(0.45 \mu \mathrm{m})$. Twenty microliters of the filtrate was injected into the HPLC system. Quantification of vitamin B content was accomplished by comparison to vitamin B standards. Standard stock solutions for thiamine (B1), riboflavin (B2), niacin (B3), pyridoxine (B6), and cobalamin (B12) were prepared as reported previously (Ringling \&Rychlik, 2013, Aslam et al 2008).

Chromatographic separation was achieved on a reversed phase- (RP-) HPLC column (Agilent ZORBAX Eclipse Plus $\mathrm{C} 18 ; 250 \times 4.6 \mathrm{~mm}$ i.d., $5 \mu \mathrm{m})$ through the isocratic delivery mobile phase (A/B 33/67; A: $\mathrm{MeOH}, \mathrm{B}: 0.023 \mathrm{M}$ $\mathrm{H} 3 \mathrm{PO} 4, \mathrm{pH}=3.54$ ) at a flow rate of $0.5 \mathrm{~mL} / \mathrm{min}$. Ultraviolet (UV) absorbance was recorded at $270 \mathrm{~nm}$ at room temperature (Marzougui et al 2009).

Vitamin C (Ascorbic Acid):-

Vitamin $\mathrm{C}$ was extracted according to a modification of a published method (Babarinde\&Fabunmi 2009). The sample powder $(10 \mathrm{~g})$ was blended and homogenized with an extracting solution containing metaphosphoric acid $(0.3 \mathrm{M})$ and acetic acid $(1.4 \mathrm{M})$. The mixture was placed in a conical flask and agitated at $10,000 \mathrm{rpm}$ for $15 \mathrm{~min}$. The mixture was the filtered through a Whatman No. 4 filter, and samples were extracted in triplicate. The ascorbic acid standard was prepared by dissolving $100 \mathrm{mg}$ of l-ascorbic acid in a metaphosphoric acid $(0.3 \mathrm{M}) /$ acetic acid (1.4 M) solution at a final concentration of $0.1 \mathrm{mg} / \mathrm{mL}$. The calibration line was converted to a linear range based on four measured concentration levels.

Quantification of ascorbic acid content was performed on an Agilent HPLC system. Chromatographic separation was achieved on an RP-HPLC column through isocratic delivery of a mobile phase (A/B 33/67; A: 0.1M potassium 
acetate, $\mathrm{pH}=4.9, \mathrm{~B}$ : acetonitrile: water [50:50]) at a flow rate of $1 \mathrm{~mL} / \mathrm{min}$. UV absorbance was recorded at $254 \mathrm{~nm}$ at room temperature.

\section{Determination of mineral elements in plant sample:-}

The mineral elements were determined using the analytical method of determining mineral constituents of food products (Hack 2000). Samples obtained through ashing were used for this procedure, which was the white fluffy mas. Five milliliters of concentrated hydrochloric acid were used to digest each ash content in a glass petridish. The mixture was transferred to $50 \mathrm{~mL}$ chemical flask using distilled water particles, which cannot dissolve and would cause contamination were filtered off using Whatman's no. 1 filter paper in a funnel. The new filterate was made up to mark in readiness for mineral nutrient determination. The elements determined include $\mathrm{Na}, \mathrm{Ca}, \mathrm{K}$, $\mathrm{P}$, $\mathrm{Mg}, \mathrm{Mn}, \mathrm{Fe}, \mathrm{Cu}$ and $\mathrm{Zn}$. The determination was made using method described by (Hack 2000) standard reagents for the various elements to be determined were prepared. The series spectrophotometer was first warmed up for 30 min. Then, the standard reagent of the elements to be determined and distilled water was used to standardize the equipment. The sample contained in $10 \mathrm{~mL}$ cuvette was then introduced into the sample chamber where the samples were read and recorded.

High Performance Liquid Chromatography (HPLC) for the Identification of A. sinensesand C.villosa:High-performance liquid chromatography (HPLC) has been widely used in the evaluation of the components of A. sinenses and C. villosa. HPLC with ultraviolet detection analyzed ligustilide and ferulic acid content in extracts of A. sinenses (J.-C. Song et al., 2007). And chrysin 7-O- ( $\beta$-D-glucopyranoside) content in extracts of C. villosa (S. Wang et al. 2007).

\section{Sample Preparation:-}

Extract $5 \mathrm{~g}$ of samples powder in a soxhlet extractor with $50 \mathrm{~mL}$-hexane for 1 hour. Evaporate the extract to dryness and redissolve in $2.5 \mathrm{~mL}$ ethanol and filter $(0.45 \mu \mathrm{m}$ Millipore, or equivalent $)$.

\section{Standard Preparation:-}

For A. sinenses Dissolve each of Z-ligustilide and ferulic acid individually in ethanol ( $1 \mathrm{mg} / \mathrm{mL})$. Z-Ligustilide is unstable in air and requires refrigeration. It must flush the standard with nitrogen and store in a freezer. For C.villosa dissolved of chrysin in ethanol $(1 \mathrm{mg} / \mathrm{mL})$.

\section{Chromatographic Conditions:-}

Apparatus: Hewlett Packard 1050 liquid chromatograph with photodiodearray detector, autosampler, and gradient pump.

Column: LichroCART 125-4 with Lichrospher 100 C-18 (5 $\mu \mathrm{m})$, Merck, or equivalent.

Pre-Column: LichroCART 4-4 with Lichrospher 100 C-18 (5 $\mu \mathrm{m})$, Merck, or equivalent.

\section{Sensory evaluation of characteristics of dietary supplement:-}

Sensory evaluation was carried out by a panel of six judges with experience in the field of food science and technology. Sensory analysis of dietary supplement produced was conducted for various sensory parameters by assigning scores between 1 to 10 for color, flavor, sweetness, firmness and desirability (Sukhcharn et al 2010).

\section{Evaluation of sexual behaviors:-}

\section{Determination of testosterone level:-}

Measurement of plasma testosterone level of rats were every five days, samples are taken about three hours after intake of the dietary supplement (date paste) all of experimental period, the rat blood samples were collected and kept on ice and then centrifuged immediately at $2000 \times \mathrm{g}$ at $4{ }^{\circ} \mathrm{C}$ for $15 \mathrm{~min}$. The obtained plasma was kept at- $80{ }^{\circ} \mathrm{C}$ until analysis. Testosterone levels were measured by Egyptian National Cancer Institute (Thawatchai et al 2012).

\section{Determination of monoamine oxidase type B inhibition:-}

The inhibitory action of the plant extracts on monoamine oxidase type B was determined by incubating a series of concentrations of the test samples in the reaction mixture, including rat brain homogenates. In brief, $2.75 \mathrm{~mL}$ Tris buffer $(0.1 \mathrm{M}, \mathrm{pH} 7.4)$ and $100 \mu \mathrm{L}$ of $0.1 \mathrm{M}$ benzylamine was mixed in a quartz cuvette which was placed in double beam spectrophotometer and followed by the addition of $150 \mu \mathrm{L}$ solution of brain homogenate to initiate the enzymatic reaction. The change in absorbance was recorded at wavelength of $249.5 \mathrm{~nm}$ for 5 min against the blank containing Tris buffer and 5-hydroxytryptamine (Xu et al 2006). 


\section{Determination of Phosphodiesterase (PDE) Activity:-}

Testis was collected from healthy male rat in order to Determine Phosphodiesterase Enzyme (PDE) activity. The testis was washed with phosphate buffer saline (PBS) and weighted before cut to small pieces. Then, it was homogenized with 5 volumes of lysate RIPA buffer $(50 \mathrm{mMTris}-\mathrm{HCl}, \mathrm{pH}=7.4)$. The testicular solution was centrifuged at $14,000 \times \mathrm{g}$ for $15 \mathrm{~min}$ at $4{ }^{\circ} \mathrm{C}$ and the supernatant was collected and used as PDE substrate. The standard curve was prepared from PDE (testicular lysate) at the various concentrations.phosphodiesterase substrate or testicular lysate was incubated with cGMP. Then, PDE reaction solutions were added and incubated for 20 min at room temperature. The cGMP in the mixture then drives a kinase reaction leading to a reduction of ATP levels. Following the kinase reaction, an Kinase Glo reagent was added and reactions were mixed and incubated for 10 min at room temperature. Luminescence was measured using a SpectraMax L microplate luminometer . The luminescent signal produced is directly related to the amount of ATP remaining and correlates with phosphodiesterase activity use remaining unit (RLU Relative Light Unit) (Thawatchai et al 2012).

\section{Nutritional Studies of dietary supplement products:-}

The dietary supplement produced was analyzed for the nutritional parameters, carbohydrate, fiber, crude protein, ash, fat and moisture were determined by the method of A.O.A.C (1990).

\section{StatisticAnalysis: -}

All data were expressed as mean \pm SEM value. The significant differences among various groups were compared by ANOVA and followed by Duncan's test. The statistical difference was regarded at $\mathrm{p}<0.05$.

\section{Results and Discussion:-}

\section{Determination of vitamins in plant sample:-}

Table 1 shows important variations of the fat-soluble vitamin compositions in the studied A.sinensis root, C. villosa (leaves and flowers), Date paste samples.TheA.sinensis root showed the highest content of vitamin E (7.2 $\mu \mathrm{g} / 100 \mathrm{~g})$, while the C. villosa had the lowest content $(0.05 \mathrm{mg} / 100 \mathrm{~g})$. No detectable quantities of vitamin K3 and D3 were observed in all samples . Date paste had significate amount of A $(0.06 \mu \mathrm{g} / 100 \mathrm{~g})$.

Table 2 shows the water-soluble vitamin contents (B1, B2, B3, B6, B12, and C) for A.sinensis root, C. villosa (leaves and flowers), Date paste samples. The vitamin C content of the A.sinensis root was approximately (29.3 $\mathrm{mg} / 100 \mathrm{~g})$, while it was rich in vitamin B2, B12 $(0.31 \mu \mathrm{g} / 100 \mathrm{~g}, 0.38 \mu \mathrm{g} / 100 \mathrm{~g})$ and had the highest content of vitamin B3 $(5.7 \mu \mathrm{g} / 100 \mathrm{~g})$.

C. villosa (leaves and flowers) showed the lowest content of vitamin C (17.4mg/100 g) and a slightly high content of vitamin B3 $(2.6 \mu \mathrm{g} / 100 \mathrm{~g})$. No detectable quantities of vitamin B2, B6 and B12 were observed. The C. villosa showed the highest vitamin B1 content $(0.59 \mu \mathrm{g} / 100 \mathrm{~g})$, whereas Date paste showed the lowest, in which value of vitamin B1 was detectable $(0.09 \mu \mathrm{g} / 100 \mathrm{~g})$. The date paste showed the lowest value of vitamin B3 $(0.12 \mu \mathrm{g} / 100 \mathrm{~g})$, but it had the highest content of vitamin $\mathrm{C}(68.9 \mathrm{mg} / 100 \mathrm{~g})$, while it was had significate amount of vitamin B2, B6 $(0.07 \mu \mathrm{g} / 100 \mathrm{~g}, 0.02 \mu \mathrm{g} / 100 \mathrm{~g})$.

Table 1:-Fat-soluble vitamin contents ofofA.sinensis root, C. villosa (leaves and flowers), Date paste

\begin{tabular}{|l|c|c|c|}
\hline Vitamins & A.sinensis & C. villosa & Date paste \\
\hline Tocopherol (vitamin E) $(\mathrm{mg} / 100 \mathrm{~g}$ DW) & $7.2^{\mathrm{a}}$ & $0.03^{\mathrm{b}}$ & ND \\
\hline Menaphthone $($ vitamin K3) $(\mathrm{mg} / 100 \mathrm{~g}$ DW) & ND & ND & ND \\
\hline Retinol $($ vitamin A) $(\mu \mathrm{g} / 100 \mathrm{~g}$ DW) & ND & ND & $0.06^{\mathrm{a}}$ \\
\hline Cholecalciferol $($ vitamin D3) $(\mu \mathrm{g} / 100 \mathrm{~g} \mathrm{DW})$ & ND & ND & ND \\
\hline
\end{tabular}

Dry weight (DW) was not detected (ND). Retinol (vitamin A) and Cholecalciferol (vitamin D3) are expressed in $\mu$ g per 100 gTocopherol (vitamin E) and Menaphthone (vitamin K3) are expressed in mg per 100g 
Table 2:-Water-soluble vitamin contents of ofA.sinensis root, C. villosa (leaves and flowers), Date paste.

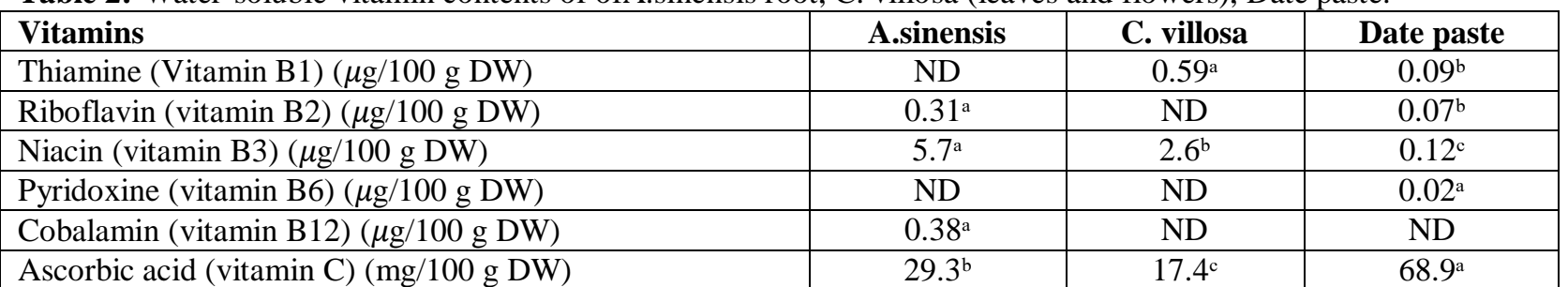

Dry weight (DW) was not detected (ND). Thiamine (Vitamin B1) Riboflavin (B2), niacin (B3), pyridoxine (B6), and cobalamin (B12) are expressed in $\mu \mathrm{g}$ per $100 \mathrm{~g}$. Ascorbic acid (C) is expressed in mg per $100 \mathrm{~g}$

\section{Determination of mineral elements in plant sample:-}

Table 3 shows the values obtained for minerals (calcium, phosphorus, iron, zinc, magnesium, manganese, coper, potassium and sodium), In the A.sinensis root; sodium and zinc content of is no detectable quantities and it had the lowest measured amount of manganese and coper among the others sample $(0.02 \mathrm{mg} / 100 \mathrm{~g}$ and $0.05 \mathrm{mg} / 100 \mathrm{~g}$ for manganese and coper respectively) but A.sinensis is the richest regarding of iron, potassium, calcium, phosphorus and magnesium contents in compare with C. villosa (leaves and flowers) and Date paste ( $82 \mathrm{mg} / 100 \mathrm{~g}, 1430$ $\mathrm{mg} / 100 \mathrm{~g}, 246 \mathrm{mg} / 100 \mathrm{~g}, 293 \mathrm{mg} / 100 \mathrm{~g}$, and $218 \mathrm{mg} / 100 \mathrm{~g}$ ) for of iron, potassium, calcium, phosphorus and magnesium respectively.

The C. villosa contains the significant amount of the zinc $(0.78 \mathrm{mg} / 100 \mathrm{~g})$ on the other hand it contains the lowest amount of minerals among the analyzed samples.

Date paste contains calcium $54 \mathrm{mg} / 100 \mathrm{mg}$, potassium $627 \mathrm{mg} / 100 \mathrm{mg}$, zinc $1.9 \mathrm{mg} / 100 \mathrm{~g}$, iron, 3mg/100g sodium $81 \mathrm{mg} / 100 \mathrm{gm}$, coper $0.42 \mathrm{mg} / 100 \mathrm{~g}$, phosphorus $106 \mathrm{mg} / 100 \mathrm{~g}$, magnesium $64 \mathrm{mg} / 100 \mathrm{~g}$ and manganese 0.63 $\mathrm{mg} / 100 \mathrm{~g}$. The date paste contains riche amount of several kinds of minerals, that human need every day with varying percentage.

Table 3:- Mineral element composition on dry weight basis of A.sinensis root, C. villosa (leaves and flowers), Date paste $(\mathrm{mg} / 100 \mathrm{~g})$

\begin{tabular}{|l|l|l|l|l|l|l|l|l|l|}
\hline & $\mathrm{K}$ & $\mathrm{Na}$ & $\mathrm{Mn}$ & $\mathrm{Ca}$ & $\mathrm{Zn}$ & $\mathrm{Fe}$ & $\mathrm{Mg}$ & $\mathrm{Cu}$ & $\mathrm{P}$ \\
\hline A.sinensis & $1430^{\mathrm{a}}$ & - & $0.02^{\mathrm{c}}$ & $246^{\mathrm{a}}$ & - & $82^{\mathrm{a}}$ & $218^{\mathrm{a}}$ & $0.05^{\mathrm{c}}$ & $293^{\mathrm{a}}$ \\
\hline C. villosa & $0.29^{\mathrm{c}}$ & $0.02^{\mathrm{b}}$ & $0.37^{\mathrm{b}}$ & $0.07^{\mathrm{c}}$ & $0.78^{\mathrm{b}}$ & $0.53^{\mathrm{c}}$ & $0.04^{\mathrm{c}}$ & $0.41^{\mathrm{b}}$ & $0.05^{\mathrm{c}}$ \\
\hline Date paste & $627^{\mathrm{b}}$ & $81^{\mathrm{a}}$ & $0.63^{\mathrm{a}}$ & $54^{\mathrm{b}}$ & $1.9^{\mathrm{a}}$ & $3^{\mathrm{b}}$ & $64^{\mathrm{b}}$ & $0.42^{\mathrm{a}}$ & $106^{\mathrm{b}}$ \\
\hline
\end{tabular}

High Performance Liquid Chromatography (HPLC) for the Identification of A. sinensesand C. villosa:Chromatography of HPLC extracts from Angelica root were shown in Fig. 1. All the main components were separated completely, and 13 of them were identified by comparing the standard, peaks 1-13 were identified as coniferylferulate, Senkyunolide A, Butylphthalide, E-Ligustilide, E-But ylidenephthalide, Z-Ligustilide, ZButylidenephthalide, Falcarindiol, Tokinolide B, Ferulic acid, Riligustulide, levistolide A, linoleic acid. The structures are shown in Fig. 1. The results are summarized in Table 4.

Table 4:- The identification of peaks was determined using HPLC from Angelica sinensis

\begin{tabular}{|c|c|c|}
\hline Peak no. & Compound & Rt (min) \\
\hline 1 & coniferylferulate & 6.9 \\
\hline 2 & Senkyunolide A & 7.2 \\
\hline 3 & Butylphthalide & 8.1 \\
\hline 4 & E-Ligustilide & 10.7 \\
\hline 5 & E-Butylidenephthalide & 12.3 \\
\hline 6 & Z-Ligustilide & 12.8 \\
\hline 7 & Z-Butylidenephthalide & 16.4 \\
\hline 9 & Falcarindiol & 17.6 \\
\hline
\end{tabular}




\begin{tabular}{|l|l|r|}
\hline 10 & Ferulic acid & 21.9 \\
\hline 11 & riligustulide & 22.6 \\
\hline 12 & levistolide A & 26.4 \\
\hline 13 & linoleic acid & 28.7 \\
\hline
\end{tabular}

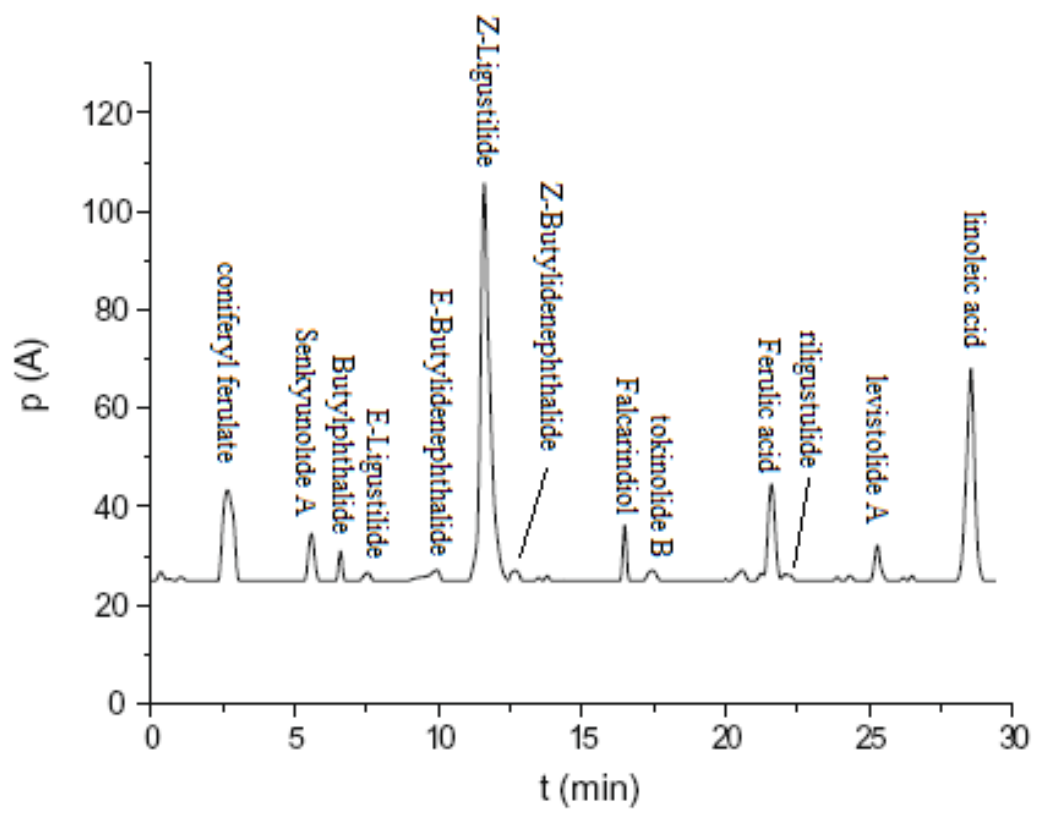

Figure 1:-HPLC fingerprint chromatogram of (Angelica sinensis)

Chromatography of HPLC extracts from calycotomevillosa were shown in Fig 2. All the main components were separated completely, and 11 of them were identified by comparing the standard, peaks 1-11 were identified as Chrysin, Genistein, Apigenin, Luteolin, Orientin, Eriodyctiol, Calycosin, Kaempferol, Butein, Calythropsin, Triterpene lupeol. The structures are shown in Fig 2. The results are summarized in Table 5.

Table 5:- The identification of peaks was determined using HPLC from calycotomevillosa

\begin{tabular}{|c|c|c|}
\hline Peak no. & Compound & Rt (min) \\
\hline 1 & Chrysin & 6.9 \\
\hline 2 & Genistein & 7.2 \\
\hline 3 & Apigenin & 8.1 \\
\hline 4 & Luteolin & 10.7 \\
\hline 5 & Orientin & 12.3 \\
\hline 6 & Eriodyctiol & 12.8 \\
\hline 7 & Calycosin & 16.4 \\
\hline 8 & Kaempferol & 17.6 \\
\hline 9 & Butein & 21.9 \\
\hline 10 & Calythropsin & 22.6 \\
\hline 11 & Triterpene lupeol & \\
\hline
\end{tabular}




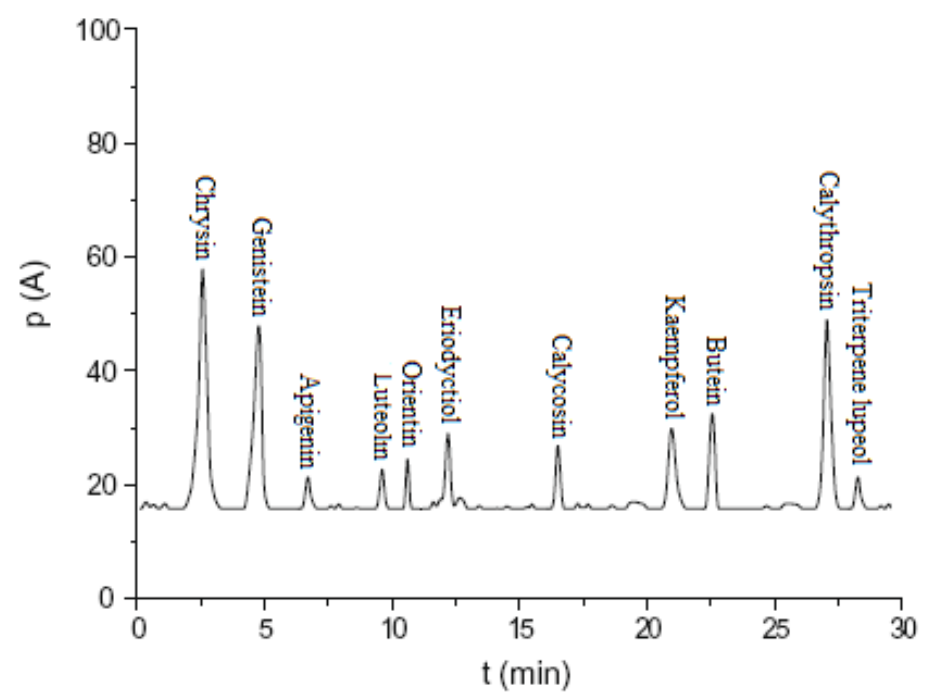

Figure 2:-HPLC fingerprint chromatogram of calycotomevillosa

\section{Sensory evaluation of characteristics of dietary supplement:-}

Figure 3 present the results of dietary supplement (DS) from date paste with different concentration additives of Angelica sinensis and calycotomevillosa powders compared with date paste without additives. Evaluation of color, firmness, sweetness, flavor and desirability of dietary supplements were considered. Color is important sensory quality attribute of date paste because it's the first property consumers observes, and losses of color are a primary concern to consumers. Addition of plants powder to date paste caused a darker paste which disliked by panelist. This dislike was proportional to the \% of plant additives used giving DS(D) the lowest score. Firmness of DS(A) was preferred than other attributes, whereas paste was the lowest score. This was due to the higher content of moisture as same control sample (date paste without additives ).

Sweetness of dietary supplement accepted more and gradually decreases with increasing of plant concentration $\%$ in date paste that it converted to bitter taste. Flavor also had a same pattern as sweetness; the increase of plants amount used reduces the sweetness and flavor of dietary supplement. The general desirability of the dietary supplement with the highest score followed by $\mathrm{DS}(\mathrm{A})>\mathrm{DS}(\mathrm{B})>\mathrm{DS}(\mathrm{C})>\mathrm{DS}(\mathrm{D})$. Based on these results we can conclude that increasing amount of plants powder to paste gradually reduce the acceptance of color, sweetness and flavor, whereas their firmness was preferred. So we can conclude that the treatment DS (B) dietary supplement with concentration $0.5 \mathrm{~g}$ was the best result by panelist.

Fig 3:- Sensory evaluation of characteristics of dietary supplement

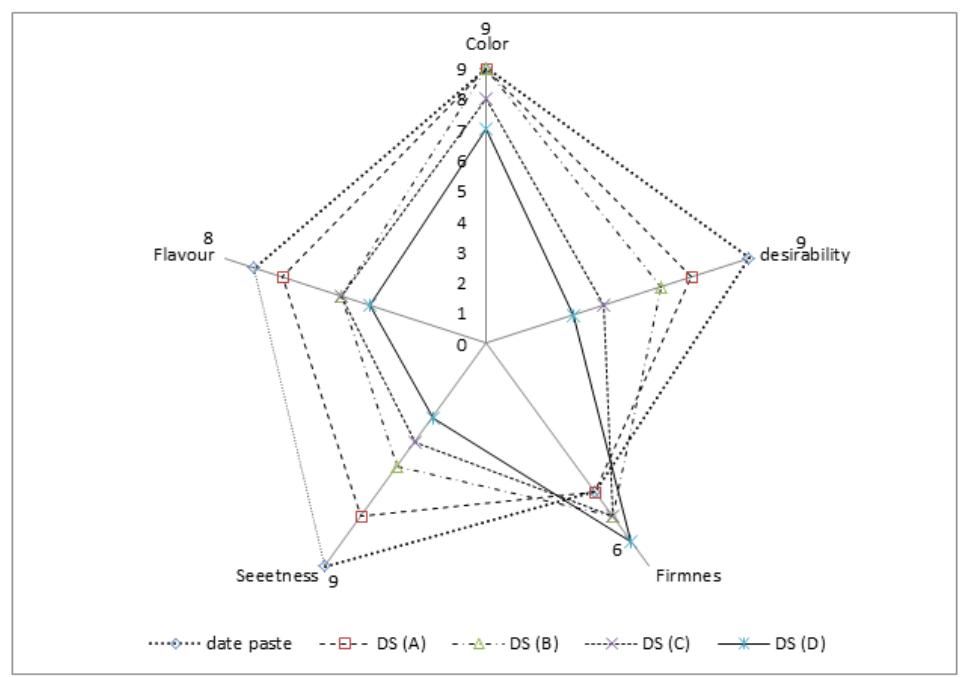


(DS) Dietary Supplement (date paste with A.sinensis and C.villosa, (A) concentration 0.25g, (B) concentration $0.5 \mathrm{~g}$, (C) concentration $0.75 \mathrm{~g}$, (D) concentration $1 \mathrm{~g}$ - date paste is control sample without plant powder

\section{Evaluation of sexual behaviors:-}

\section{Determination of monoamine oxidase type $B$ inhibition:-}

The effect of dietary supplement (DS) on MAO-B activity was evaluated and the results were shown in Fig. 4. Data clearly revealed that the effect of different concentration of Angelica sinensis and CalycotomeVillosa (0,25g (A), $0.50 \mathrm{~g}(\mathrm{~B}), 0.75 \mathrm{~g}(\mathrm{C})$ and (D)) could significantly suppress MAO-B activity (p-value <0.05) respectively; compared to control. Sildenafil citrate which was used as positive control could non-significantly suppress MAO-B activity (P $<0.05)$.

Fig 4:-Determination of monoamine oxidase type B inhibition

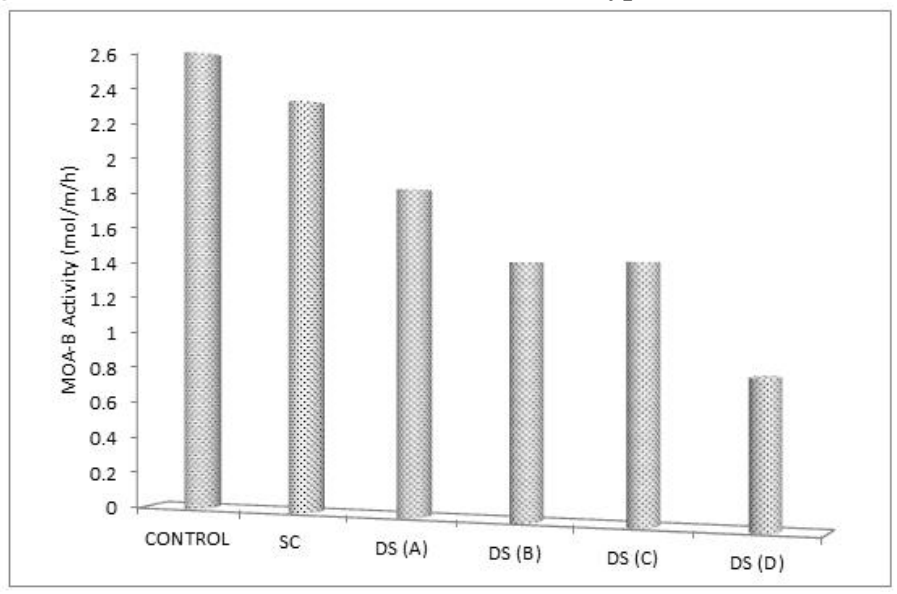

(DS) Dietary Supplement (date paste with A.sinensis and C.villosa, (A) concentration 0.25g, (B) concentration $0.5 \mathrm{~g}$, (C) concentration $0.75 \mathrm{~g}$, (D) concentration $1 \mathrm{gData}$ were presented as mean $\pm \mathrm{SEM} \mathrm{P}$-value $<0.05$ compared with control group (SC) Sildenafil citrate.

\section{Determination of testosterone level:-}

Figure 5 demonstrated the effect of dietary supplement (DS) on testosterone level. It was found that no significant changes in testosterone levels were observed in all rats subjected to dietary supplement. Dietary supplement caused significant increase in level of testosterone $(\mathrm{P}<0.05)$ as compared with the control. Dietary supplement with concentration $1 \mathrm{~g}$ plant additives DS (D) significantly increased testosterone level as compared with the concentration A, B, and C. However, the values still significantly higher than the control group.we have found the numbers without the significant change of testosterone level with Sildenafil citrate which was used as positive control.

Fig 5:-Determination of testosterone level.

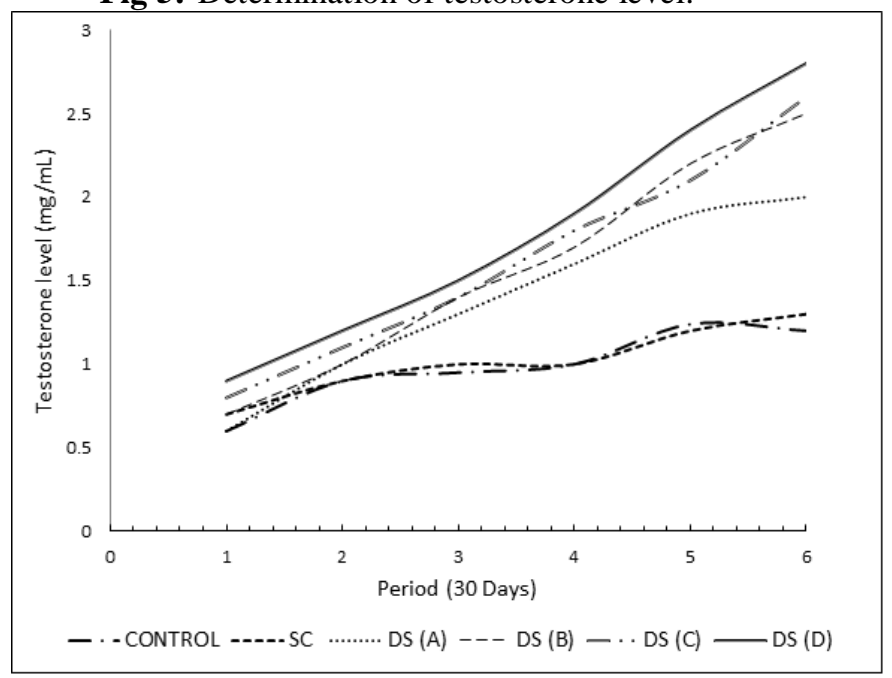


(DS) Dietary Supplement (date paste with A.sinensis and C.villosa, (A) concentration 0.25g, (B) concentration $0.5 \mathrm{~g}$, (C) concentration $0.75 \mathrm{~g}$, (D) concentration 1 gData were presented as mean \pm SEM P-value $<0.05$ compared with control group (SC) Sildenafil citrate.

Determination of Phosphodiesterase (PDE-5) Activity:-

We had determined the effect of the date paste with different concentration of Angelica sinensis and CalycotomeVillosa on the activity of PED-5 as the results were shown in Fig. 6. It was found that Sildenafil citrate which was used as positive control in this study could significantly suppress PDE-5 activity. The dietary supplement both at concentrate of $0.5 \mathrm{~g}$ DS (B) and at concentrate of $0.75 \mathrm{~g}$ DS (C) have the similar significantly affect suppressed PDE activity (p- value $<0.05$ compared to control). Dietary supplement at dose of $1 \mathrm{~g}$ could suppress PDE activity as highest effect on PDE-5 activity.

Fig 6:-Determination of Phosphodiesterase (PDE-5) activity

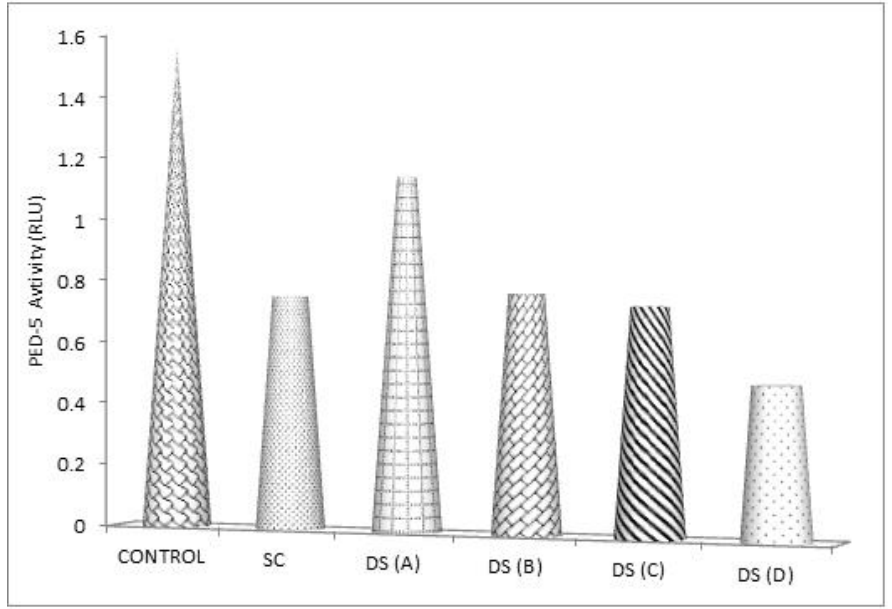

(DS) Dietary Supplement (date paste with A.sinensis and C.villosa, (A) concentration 0.25g, (B) concentration 0.5g, (C) concentration $0.75 \mathrm{~g}$, (D) concentration $1 \mathrm{gData}$ were presented as mean $\pm \mathrm{SEM}$ P-value $<0.05$ compared with control group (SC) Sildenafil citrate.

\section{Nutritional Studies of dietary supplement products:-}

Table 6 present the proximate analysis of date paste as control sample and different formulation of dietary supplement (DS). Moisture content of date paste $(15.7 \%)$ decreased significantly after adding plants powder to range between $15.2 \%$ for DS (A) to $10.8 \%$ for DS (D). The decrease of moisture content was mainly due to high content of fiber and dry powder, which has absorbed amount of water content from paste. The lower content of moisture in DS will make it more solid. Protein content of DS significantly increased (1.38-1.57\%) compare to paste (1.32\%). The fat content of DS had the same pattern as protein content in seed, ranged between $0.46 \%$ for DS (A) to $0.69 \%$ for DS (D).

Table 6:-Chemical composition of dates and seeds powder.

\begin{tabular}{|l|l|l|l|l|l|l|}
\hline & Moisture & Protein & Fat & Ash & Fiber & Carbohydrate \\
\hline $\begin{array}{l}\text { Date paste } \\
\text { (control) }\end{array}$ & $15.7^{\mathrm{a}}$ & $1.32^{\mathrm{a}}$ & $0.41^{\mathrm{a}}$ & $1.96^{\mathrm{a}}$ & $5.11^{\mathrm{a}}$ & $22.37^{\mathrm{a}}$ \\
\hline DS (A) & $15.2^{\mathrm{a}}$ & $1.38^{\mathrm{b}}$ & $0.46^{\mathrm{a}}$ & $2.08^{\mathrm{b}}$ & $5.73^{\mathrm{a}}$ & $22.61^{\mathrm{a}}$ \\
\hline DS (B) & $13.9^{\mathrm{b}}$ & $1.46^{\mathrm{b}}$ & $0.53^{\mathrm{b}}$ & $2.18^{\mathrm{c}}$ & $6.24^{\mathrm{b}}$ & $22.94^{\mathrm{b}}$ \\
\hline DS (C) & $11.6^{\mathrm{c}}$ & $1.53^{\mathrm{b}}$ & $0.62^{\mathrm{c}}$ & $2.27^{\mathrm{c}}$ & $7.18^{\mathrm{c}}$ & $23.26^{\mathrm{c}}$ \\
\hline DS (D) & $10.8^{\mathrm{c}}$ & $1.57^{\mathrm{b}}$ & $0.69^{\mathrm{c}}$ & $2.54^{\mathrm{d}}$ & $8.14^{\mathrm{d}}$ & $23.48^{\mathrm{c}}$ \\
\hline
\end{tabular}

(DS) Dietary Supplement (date paste with A.sinensis and C.villosa, (A) concentration 0.25g, (B) concentration 0.5g, (C) concentration $0.75 \mathrm{~g}$, (D) concentration $1 \mathrm{gData}$ were presented as mean \pm SEM P-value $<0.05$.

\section{Discussion:-}

The present results provide, for the first time, information concerning the ability of natural dietary supplement to improve male sexual behavior in rats. Accumulative lines of evidence have demonstrated that male sexual behavior 
is regulated mainly by neuroendocrine system and testosterone level.(Thawatchai et al 2012). Therefore, in this study we also determined the effect of the natural dietary supplement on testosterone level and MAO-B, PED5 activity.

Since monoamine oxidases type B (MAO-B), play an important role in neurodegenerative disorders. MAO-B is the main enzyme responsible for the oxidative deamination of dopamine in the brain. By inhibiting MAO-B, dopamine is increased in the brain (Billett 2004). MAO-B inhibitors are used in the treatment of depression and deficit in dopaminergic activity, Inhibition of this isoenzyme should raise the basal central level of dopamine (Yamada \&Yasuhara 2004).

Several flavonoids have been identified as inhibitors of MAO-B. Flavones may interact with the GABAA-receptor, producing sedation, anxiolytic. The flavonols and the flavones were isolated from a standardized plants extract by HPLC (Sloley et al 2000). It could be possible that the natural dietary supplement suppresses MAOB and gave rise to the elevation of dopamine. Therefore the Angelica sinensis and CalycotomeVillosacontent compounds can action as MOAB inhibitors as shown in table (7).

Eroticism lead to activate an enzyme Nitric Oxide Synthase (NOS), Which converts the amino acid L- arginine to Nitric Oxide (NO) and thus increases pose NO, Which activates Guanelel cyclase enzyme which leads to form cGMP from GTP and increases the presence in the cavernous body of the penis .The cGMP activates the protein kinase enzyme leading to the occurrence of relaxation in smooth muscle surrounding arteries in the spongy cavernous body in penis that are in the normal case was cramped. Expansion of previous vessels leading to increased blood flow to the cavernous body and not to discharged again, which lead to increase the erection of the penis (Bender \&Beavo 2006).

Cyclic nucleotide phospodiesterases (PDE5) are enzymes that regulate the cellular levels of cAMP by controlling their rates of degradation. The major PDE5 in arterial smooth muscle it has been found to be a major cGMP hydrolizing. The inhibition of PDE5 lead to increasing cGMP levels (Bender \&Beavo 2006). Several compounds, mostly flavonoids and chalcones have been described as PDE inhibitors and NO/ cGMP activators (Francisco et al 2013).

In this study, we have found that natural dietary supplement also significantly suppressed PDE-5 activity. Therefore, the possible underlying mechanism of compounds in Angelica sinensis and CalycotomeVillosamight be due to its ability to suppress PDE-5 activity together with the suppression of MAOB activity as clearly in table (7).

Table 7:-Compounds Derived from Plants and Their Mechanisms of Action Ref [25, 13]

\begin{tabular}{|c|c|c|c|c|}
\hline Compound & Plant & PED5 & MAOB & NO/CGMP \\
\hline coniferylferulate & \multirow{10}{*}{ 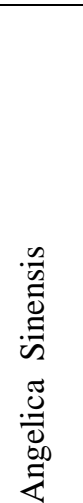 } & - & - & \\
\hline Senkyunolide A & & & - & \\
\hline Butylphthalide & & & & + \\
\hline E-Ligustilide & & - & - & \\
\hline E-Butylidenephthalide & & & & + \\
\hline Z-Ligustilide & & - & - & \\
\hline Z-Butylidenephthalide & & & & + \\
\hline Ferulic acid & & - & - & \\
\hline Riligustulide & & & - & \\
\hline levistolide A & & & - & \\
\hline Chrysin & \multirow{6}{*}{ 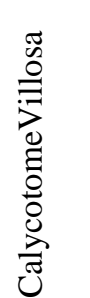 } & & - & + \\
\hline Genistein & & - & - & \\
\hline Apigenin & & & - & + \\
\hline Luteolin & & & & \\
\hline Orientin & & & & + \\
\hline Eriodyctiol & & & & + \\
\hline
\end{tabular}




\begin{tabular}{|l|l|l|l|l|}
\hline Kaempferol & & - & - & + \\
\cline { 1 - 4 } Butein & & & - & + \\
\hline
\end{tabular}

Nitric Oxide NO/cGMP pathway; PDE, phosphodiesterase; MAO-B, monoamine oxidases type B; +, activation; -, inactivation

Vitamin E a strong anti-oxidant and has the ability to cross the blood-cerebral barrier, and contributes to the creation of neurotransmitters and protects cells from the harmful effects of oxidative stress, and also has the ability to inhibit the enzyme PED5 who works the degradation of cGMP (Alves 2015). All kinds of vitamin B, potassium and magnesium have increased the efficiency of Neurology, one of the most important anti-depressant substances which inhibit the of enzyme MAO-B activity, as it increases the level of testosterone in the body (FAO/WHO 2004). The presence of vitamins $\mathrm{C}$, A and minerals such as phosphorus, zinc and potassium, have particular importance, it increases the male sex hormone testosterone levels in the blood, and also hinder the process of converting testosterone to estrogen they stop an enzyme aromatase, which converts testosterone to estrogen that helps increase testosterone levels, deficiency of potassium and zinc is always associated with low testosterone levels. Phosphorus helps build (Phospholipids) in the body, such as lecithin, which plays an important role in the production of sex hormones (FAO/WHO 2004). The results were shown in table (1, 2 and 3) we have found that natural dietary supplement significantly improved testosterone level. Therefore, the possible underlying mechanism of vitamins and mineral in date paste, Angelica sinensis and CalycotomeVillosamight be due to its ability to increase testosterone level.

\section{Conclusion:-}

Enhance male sexual desire and performance. This enhancement can be ascribed to the suppression of MAOB and phosphodiesterase activities and improved testosterone level. Therefore, date paste with Angelica sinensis and CalycotomeVillosa may be served as the natural resource for developing functional food and food supplement to reduce male dysfunction. The dietary supplement was produced in this study is a potential agent to manage sexual dysfunction especially for acute and short term application.

\section{References:-}

1. Alves FS, Freitas FG, Bafi AT, Azevedo LC, Machado FR. (2015). Serum concentrations of vitamin D and organ dysfunction in patients with severe sepsis and septic shock. Rev Bars TerIntensiva. 27(4): 376-382.

2. Anthony G. Payne (2010). Improving Male Sexual Responsiveness \& Performance. PhD, (Rush University Medical Center, Chicago, IL).

3. AOAC International, Official Methods of Analysis, Arlington, Va, USA, 15th edition, (1990).

4. Aumaporn, (2009). Effects of moisture heating and vacuum fry on organic and conventional okra quality, Asian Journal of Food and Agro-Industry, vol. 2, pp. S318-S324

5. Bender, A.T.; Beavo, J.A. (2006). Cyclic nucleotide phosphodiesterases: molecular regulation to clinical use. Pharmacol. Rev. 58, 488-520.

6. Billett, E.E. (2004). Monoamine oxidase (MAO) in human peripheral tissues. Neurotoxicology, 25, 139-148..

7. C. H. Jun,G. B. Zhong, L.C. Ying, L. H. Guang, Y. Q. Li, and L. R. Jun, (2007). "Study on content determination of vitamin A and E in white yak's milk by HPLC," Journal of Gansu Agricultural University, vol. 2, pp. 108-111.

8. C. Ringling andM. Rychlik, (2013). "Analysis of seven folates in food by LC-MS/MS to improve accuracy of total folate data," European Food Research and Technology, vol. 236, pp. 17-28

9. Chang HM, But PP. (1987). Pharmacology and Application of Chinese Material Medica, Vol 1. Singapore: World Scientific; 489-505.

10. Der Marderosian A, Beutler J, eds. (2004). The Review of Natural Products. St. Louis, MO; Facts and Comparisons Publishing Group.

11. Duke JA. (1992). Handbook of Phytochemical Constituents of GRAS Herbs and Other Economic Plants. Boca Raton, FL: CRC Press.

12. FAO/WHO. (2004). expert consultation on human vitamin and mineral requirements. World Health Organization and Food and Agriculture Organization of the United Nations.

13. Francisco J. Luna-Vázquez, César Ibarra-Alvarado, Alejandra Rojas-Molina, Isela Rojas-Molina and Miguel Ángel Zavala-Sánchez. (2013). Vasodilator Compounds Derived from Plants andTheir Mechanisms of Action. Molecules. 18, 5814-5857.

14. G. O. Babarinde and O. A. Fabunmi, (2009). "Effects of packing materials and storage temperature on quality of fresh okra (Abelmoschusesculentus L.) fruit," AgriculturaTropica et Subtropica, vol. 42, pp. 151-156. 
15. Glenville, M., (2008). The nutritional approach to male factor infertility.Dragons Tale, 18:4-5.

16. Hack, B., (2000). Analytical method of determination of mineral nutrients. In: Text on Analytical in practice. Dolphin and John S 1st Edn. NY. Incorp Press Ltd., pp: 26-33.

17. Huang KC. (1999). The Pharmacology of Chinese Herbs. 2nd ed. Boca Raton, FL: CRC Press.

18. J. Aslam, M. S. Mohajir, S. A. Khan, and A. Q. Khan, (2008). "HPLC analysis of water-soluble vitamins (B1, B2, B3, B5, B6) in in vitro and ex vitro germinated chickpea (Cicer arietinum L.)," African Journal of Biotechnology, vol. 7, no. 14, pp. 2310-2314.

19. Juan Arroyo, AbelardoAparicio, Rafael G. Albaladejo, Joaquín Muñoz† And Rita Braza., (2008). Genetic structure and population differentiation of the Mediterranean pioneer spiny broom Calicotomevillosa across the Strait of Gibraltar. Biological Journal of the Linnean Society, 93, 39-51

20. K. Nandeesh, R. Jyotsna And G. Venkateswara Rao.(2010). Effect Of Differently Treated Wheat Bran On Rheology, Microstructure And Quality Characteristics Of Soft Dough Biscuits. Journal of Food Processing and Preservation 35, 179-200.

21. Moreira, E.D., S.C. Kim, D. Glasser and C. Gingell, (2006). Sexual activity, prevalence of sexual problems and associated help-seeking patterns in men and women aged 40-80 years in Korea: data from the Global Study of Sexual Attitudes and Behaviors (GSSAB). J. Sex Med., 3: 201-211.

22. N. Marzougui, F. Guasmi,M.Mkaddem et al., (2009). "Assessment of Tunisian Trigonellafoenumgraecum diversity using seed vitamin B6, B1, B9 and C contents," Journal of Food, Agriculture and Environment, vol. 7, no. 1 , pp. 56-61.

23. NeeleshMalviya, Sanjay Jain, Vipin Bihari Gupta And Savita Vyas. (2011). Recent Studies On Aphrodisiac Herbs For The Management Of Male Sexual Dysfunction. ActaPoloniaePharmaceutica-Drug Research, Vol. 68 No. 1 pp. $3-8$,

24. Skidmore-Roth L. Mosby's (2001).Handbook of Herbs \& Natural Supplements. St. Louis, MO: Mosby, Inc;

25. Sloley, B.D.; Urichuk, L.J.; Morley, P.; Durkin, J.; Shan, J.J.; Pang, P.K.T.; Coutts, R.T. (2000). Identification of kaempferol as a monoamine oxidase inhibitor and potential neuroprotectant in extracts of Ginkgo biloba leaves. J. Pharm. Pharmacol. 52, 451-459.

26. Sukhcharn Singh, C. S. Riar and D. C. Saxena.(2010). Effect of incorporating sweetpotato flour to wheat flour on the quality characteristics of cookies. African Journal of Food Science. Vol (2) pp. 065-072

27. ThawatchaiPrabsattroo, JintanapornWattanathorn, SitthichaiIamsa-ard, SupapornMuchimapura and WipaweeThukhammee., (2012). MoringaOleifera Leaves Extract Attenuates Male Sexual Dysfunction. American Journal of Neuroscience 3 (1): 17-24.

28. Tyler VE. (1995). The Honest Herbal: A Sensible Guide to the Use of Herbs and Related Remedies. 3rd ed. New York, NY: Pharmaceutical Products Press.

29. Wattanathorn, J., P. Pangphukiew, S. Muchimapura, K. Sripanidkulchai and B. Sripanidkulchai, (2012). Aphrodisiac activity of Kaempferiaparviflora. Am. J. Agric. Biol. Sci., 7: 114-120. DOI: 10.2844/ajabssp. 114.120

30. Wilasrusmee C, Kittur S, Siddiqui J, et al. (2002). In vitro immunomodulatory effects of ten commonly used herbs on murine lymphocytes. J Altern Complement Med;8:467-475.

31. Wilasrusmee C, Siddiqui J, Bruch D, et al. (2002). In vitro immunomodulatory effects of herbal products. Am Surg;68:860-864.

32. Xu, Y., B.S. Ku, H.Y. Yao, Y.H. Lin and X. Ma et al., (2005). The effects of curcumin on depressive-like behaviors in mice. Eur. J. Pharmacol., 518: 40-46.

33. Yamada, M.; Yasuhara, H. (2004). Clinical pharmacology of MAO inhibitors: Safety and future. Neurotoxicology, 25, 215-221.

34. Zhu DP. (1987). Dong quai. Am J Chin Med;15:117-125. 